\title{
LA-UR-18-28521
}

Approved for public release; distribution is unlimited.

Title:

Author(s):

Issued:
Advanced Integration

Key, Brian P.

Tutt, James Robert

Fugate, Michael Lynn

Intended for: Report

2018-09-06 
Disclaimer:

Los Alamos National Laboratory, an affirmative action/equal opportunity employer, is operated by the Los Alamos National Security, LLC for the National Nuclear Security Administration of the U.S. Department of Energy under contract DE-AC52-06NA25396. By approving this article, the publisher recognizes that the U.S. Government retains nonexclusive, royalty-free license to publish or reproduce the published form of this contribution, or to allow others to do so, for U.S. Government purposes. Los Alamos National Laboratory requests that the publisher identify this article as work performed under the auspices of the U.S. Department of Energy. Los Alamos National Laboratory strongly supports academic freedom and a researcher's right to publish; as an institution, however, the Laboratory does not endorse the viewpoint of a publication or guarantee its technical correctness. 


\section{Advanced Integration}

James Tutt (NEN-5) Mike Fugate (CCS-6) Brian Key (NEN-5)

September 12, 2018

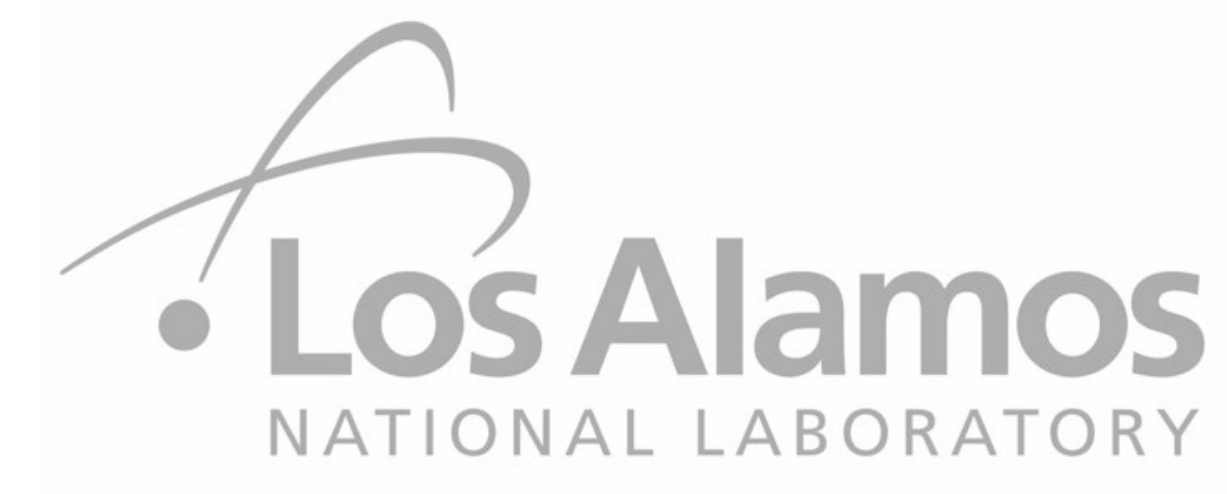




\section{Outline}

- Current Data Set being used

- Current Results for MC Modeling and Statistical Modeling of the High Dose Neutron Detector (HDND)

- Current work on new Microcal Data and Results

- Current work on Voltammetry Data 


\section{Current Framework for Advanced Integration}

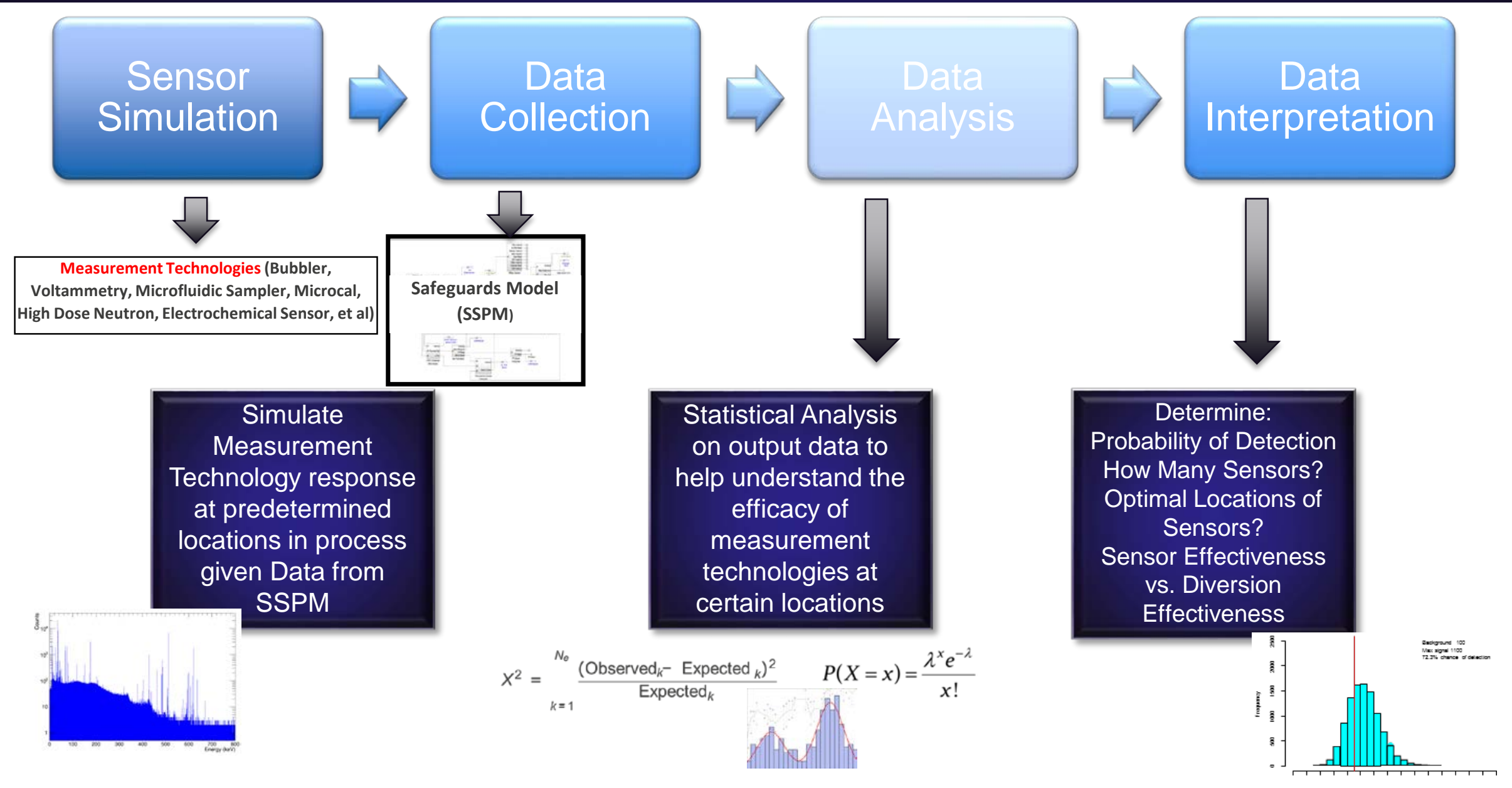




\section{New Data Generation from SSPM - SNL, Cipiti}

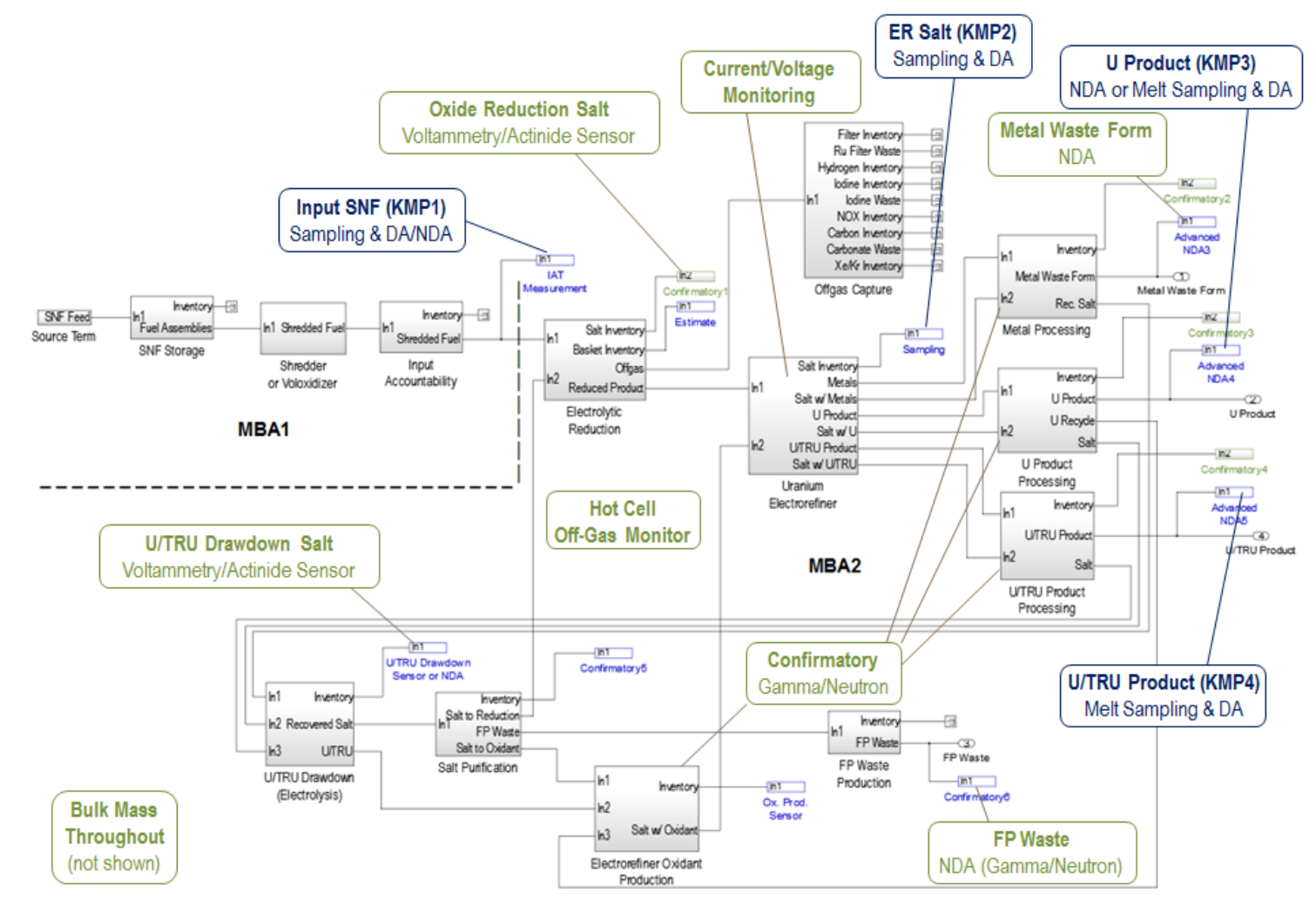




\section{Data Gathering and Distribution}

- Received detailed, time dependent plant isotopics from SNL

- Working with measurement technology groups to develop simulated responses based on material compositions in each process

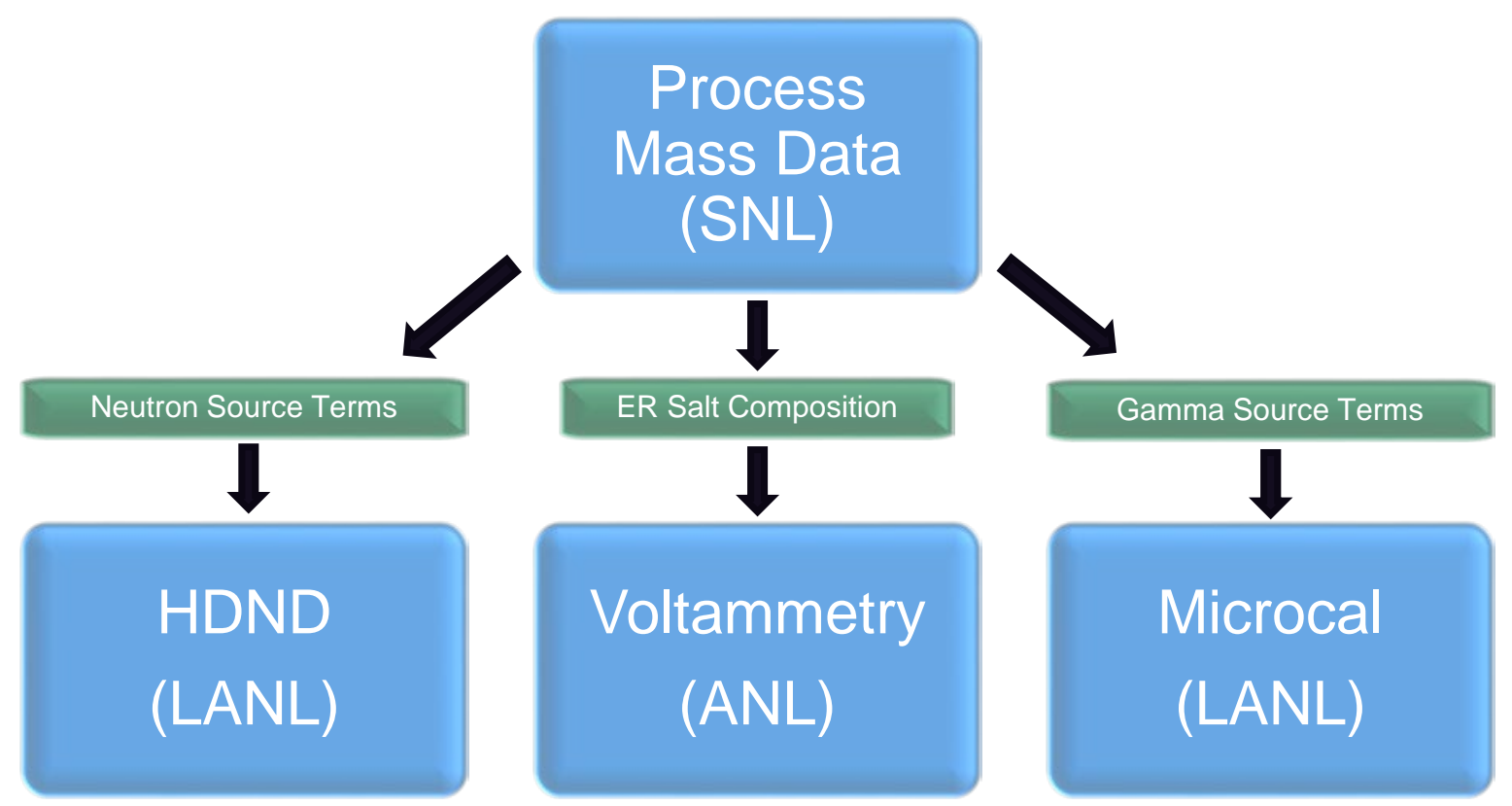




\section{High Dose Neutron Detector (HDND)}




\section{HDND Measurement Locations}

\section{- U Product}

- Ensure no Pu in ingot

- U/TRU Product

- Actinide accountability

- Confirmatory Measurements

- Metal Processing

- U Product Processing

- U/TRU Product Processing

- ER Oxidant Production
Figure from SSPM - Cipiti

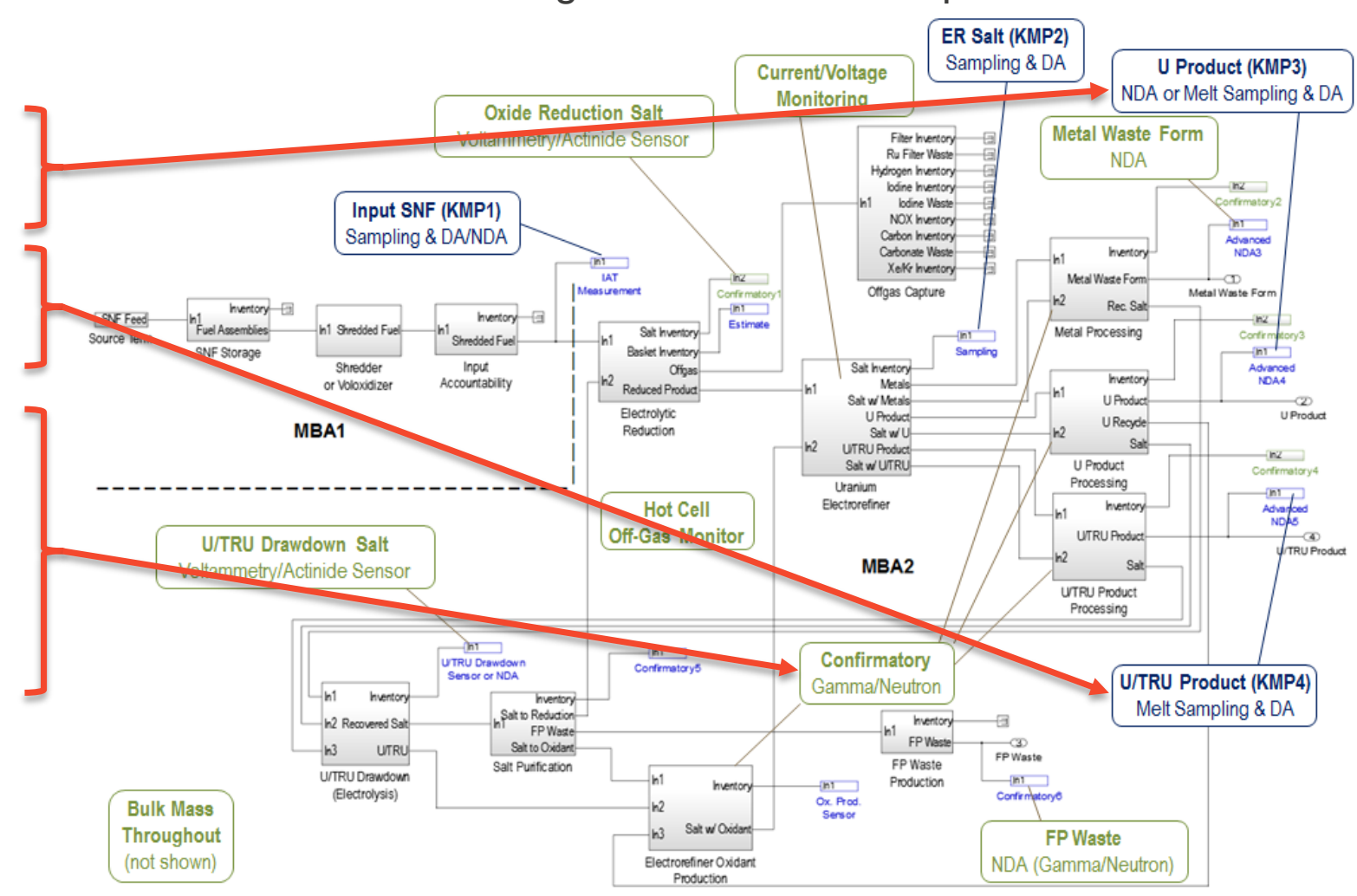




\section{U Product Neutron Signatures}

- Masses and isotopics from SSPM (Cipiti)

- Sources of neutrons

- Alpha-n reactions (negligible in $U$ and U/TRU ingots)

- Spontaneous fission (primary source of neutron emissions)

- Multiplication in material

- Induced fission

- $(n, x n)$

- Source terms

- $U$ product in normal operation

- U product with $1 \% \mathrm{Pu}$ isotopics added

- U product with 1\% U/TRU product isotopics added

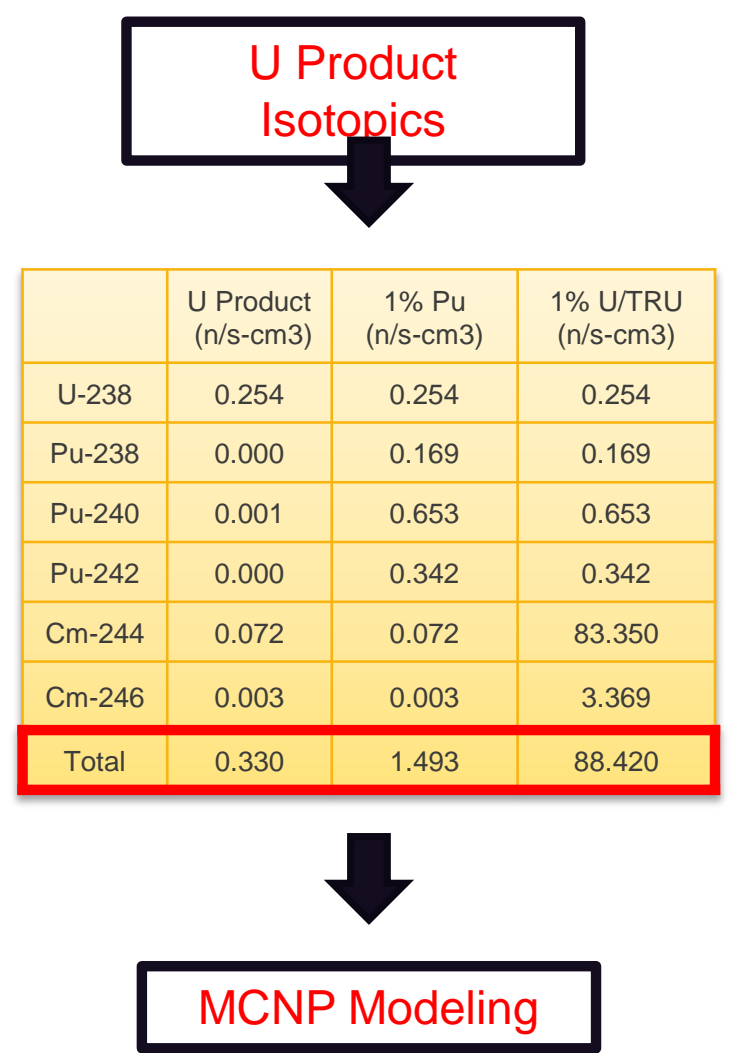




\section{HDND MC Modeling}

- MCNP model of HDND detector

- Use neutron source term created from isotopic data

- Represent U product ingots in model

- Count neutron captures in ${ }^{10} \mathrm{~B}$ that result in an energy deposition within the C10 gas sufficient to generate a pulse

- Rate of captures gives estimate of total neutron detection efficiency
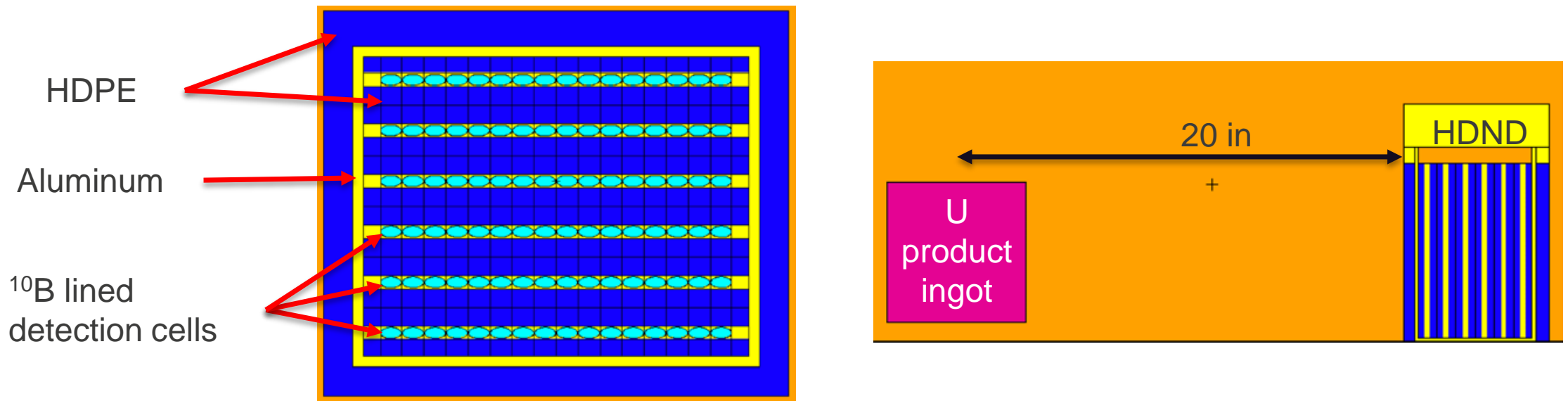


\section{HDND Statistical Modeling}

- From MC modeling we expect the following count rates for U Product and U/TRU Product

\begin{tabular}{|c|c|c|c|}
\hline & U Product & UTRU Product & \\
\hline & pulses $/ \mathrm{s}$ & pulses/s & Dnolsm \\
\hline Normal & 7.9 & 66098.1 & No Backgrc \\
\hline $1 \% \mathrm{Pu}$ & 36.8 & 64640.4 & -This will be th \\
\hline $1 \%$ UTRU & 2192.6 & 64311.5 & \\
\hline
\end{tabular}

- Statistical methods will use 5 minute and 10 minute count rates 


\section{Probability of Detection (U Product)}

\begin{tabular}{|l|c|c|}
\hline & U Product & UTRU Product \\
\hline & pulses/s & pulses/s \\
\hline Normal & 7.9 & 66098.1 \\
\hline $1 \% \mathrm{Pu}$ & 36.8 & 64640.4 \\
\hline
\end{tabular}

- Neutron counts are modeled as a Poisson Distribution

- Z statistic used to detect a difference in counts

$$
Z=\frac{\text { observed }- \text { expected }}{\sqrt{\text { expected }}}
$$

- With a diversion of $\mathrm{Pu}$, observed count rate will be larger, therefore $Z$ will be large

- For a 5\% False Alarm rate:

$Z<1.645$ (95 ${ }^{\text {th }}$ quantile of std Gaussian)

- Very High Probability of detection of Pu in U Product (7.9 vs 36.8 )

\section{5 min count rate, $1 \% \mathrm{Pu}$}

$$
\begin{aligned}
Z & =\frac{(5 \cdot 60 \cdot 36.8)-(5 \cdot 60 \cdot 7.9)}{\sqrt{5 \cdot 60 \cdot 7.9}} \\
& =\sqrt{300} \cdot \frac{(36.8-7.9)}{\sqrt{7.9}} \approx 178 .
\end{aligned}
$$

99.999th quantile of std Gaussian $=4.26$ 


\section{Probability of Detection (U Product)}

U Product

\begin{tabular}{|l|c|c|}
\hline & U Product & UTRU Product \\
\hline & pulses/s & pulses/s \\
\hline Normal & 7.9 & 66098.1 \\
\hline $1 \% \mathrm{Pu}$ & 36.8 & 64640.4 \\
\hline
\end{tabular}

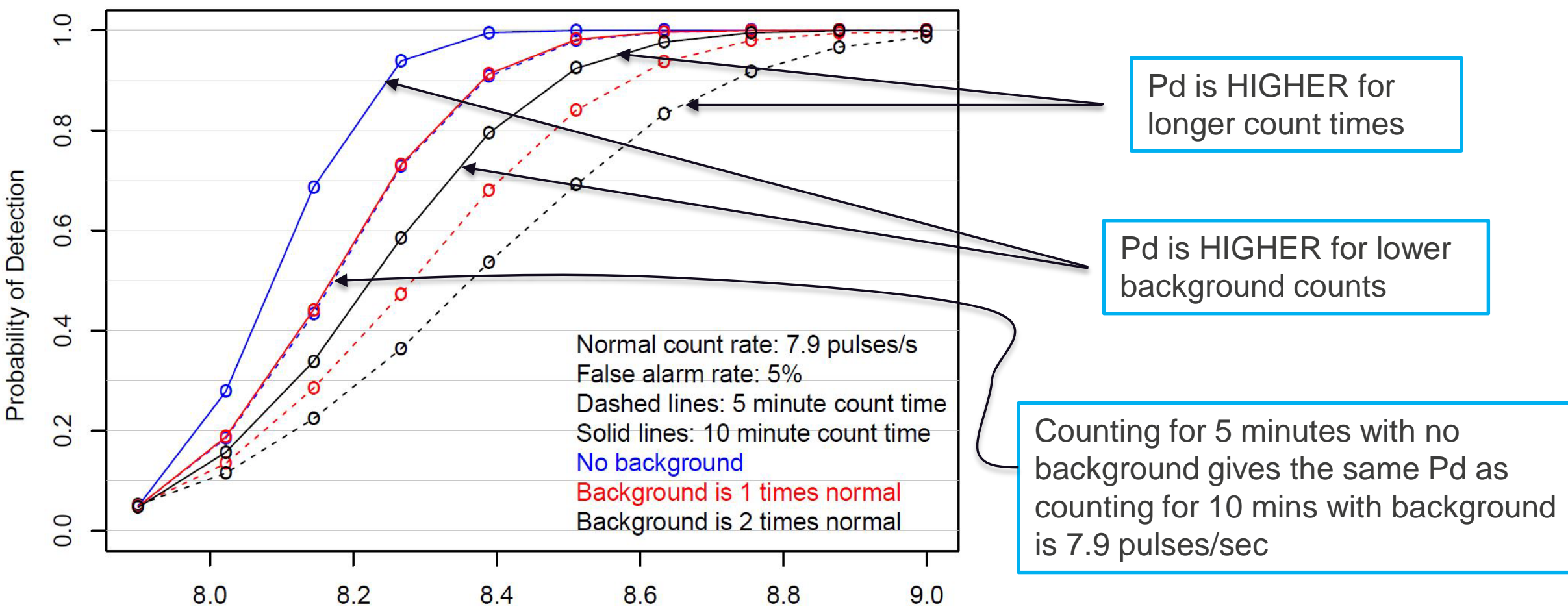

No Background Count Rates (pulses/s) 


\section{Probability of Detection (U Product)}

\begin{tabular}{|l|c|c|}
\hline & U Product & UTRU Product \\
\hline & pulses/s & pulses/s \\
\hline Normal & 7.9 & 66098.1 \\
\hline $1 \% \mathrm{Pu}$ & 36.8 & 64640.4 \\
\hline
\end{tabular}

\section{U Product}

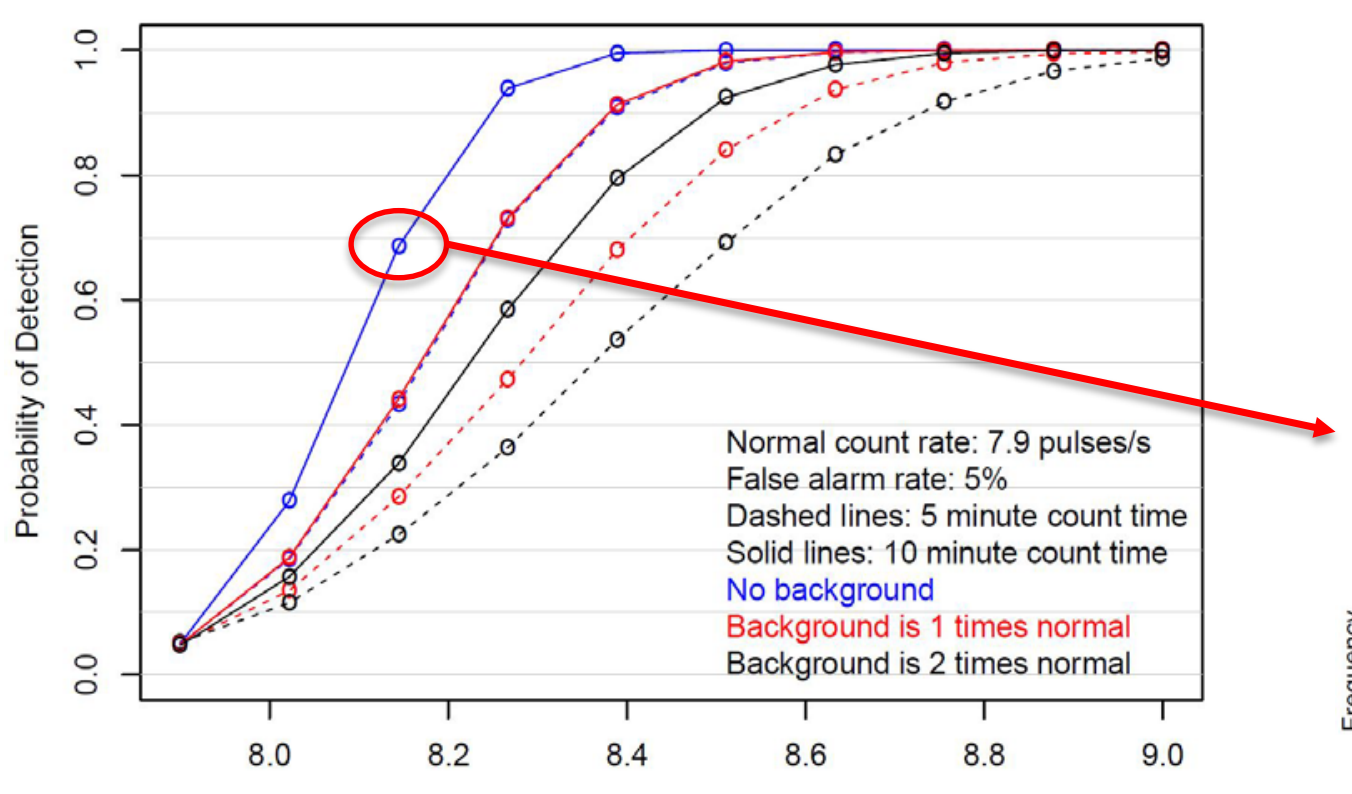

No Background Count Rates (pulses/s)
For every circle, $\mathrm{Pd}$ is estimated by counting how many times the statistic $Z$ exceeds threshold (1.645) using 100000 Poisson Samples

\section{U Product with Some Pu}

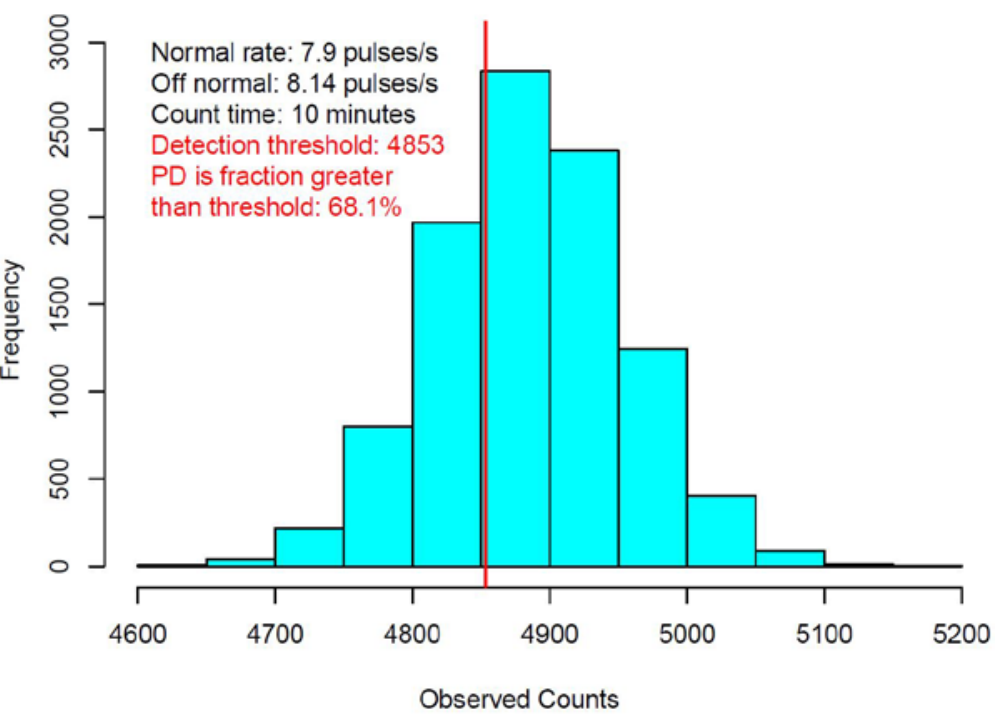




\section{Probability of Detection (UTRU Product)}

\begin{tabular}{|l|c|c|}
\hline & U Product & UTRU Product \\
\hline & pulses/s & pulses/s \\
\hline Normal & 7.9 & 66098.1 \\
\hline $1 \% \mathrm{Pu}$ & 36.8 & 64640.4 \\
\hline
\end{tabular}

- Neutron counts go down with a diversion of $\mathrm{Pu}$

- Due to counts being so high, easy to detect small decreases

$$
Z=\frac{\text { observed }- \text { expected }}{\sqrt{\text { expected }}}
$$

- With a diversion of $\mathrm{Pu}$, observed count rate will be smaller, therefore $Z$ will be a large negative

- For a 5\% False Alarm rate:

$Z<1.645$ (95 ${ }^{\text {th }}$ quantile of std Gaussian)

- $\quad$ Very High Probability of detection of Pu in $\underline{\text { UTRU Product }}$

$$
\mathrm{Z}=\frac{(64640.4-66098.1)}{\sqrt{64640.4}} \sim-5.7
$$

5 min count rate, $1 \% \mathrm{Pu}$

$$
\sqrt{300}(-5.7) \sim-98
$$

98 standard deviations from no diversion mean $0.00001^{\text {th }}$ quantile of std Gaussian $=-4.26$ 


\section{Probability of Detection (UTRU Product)}

U/TRU Product

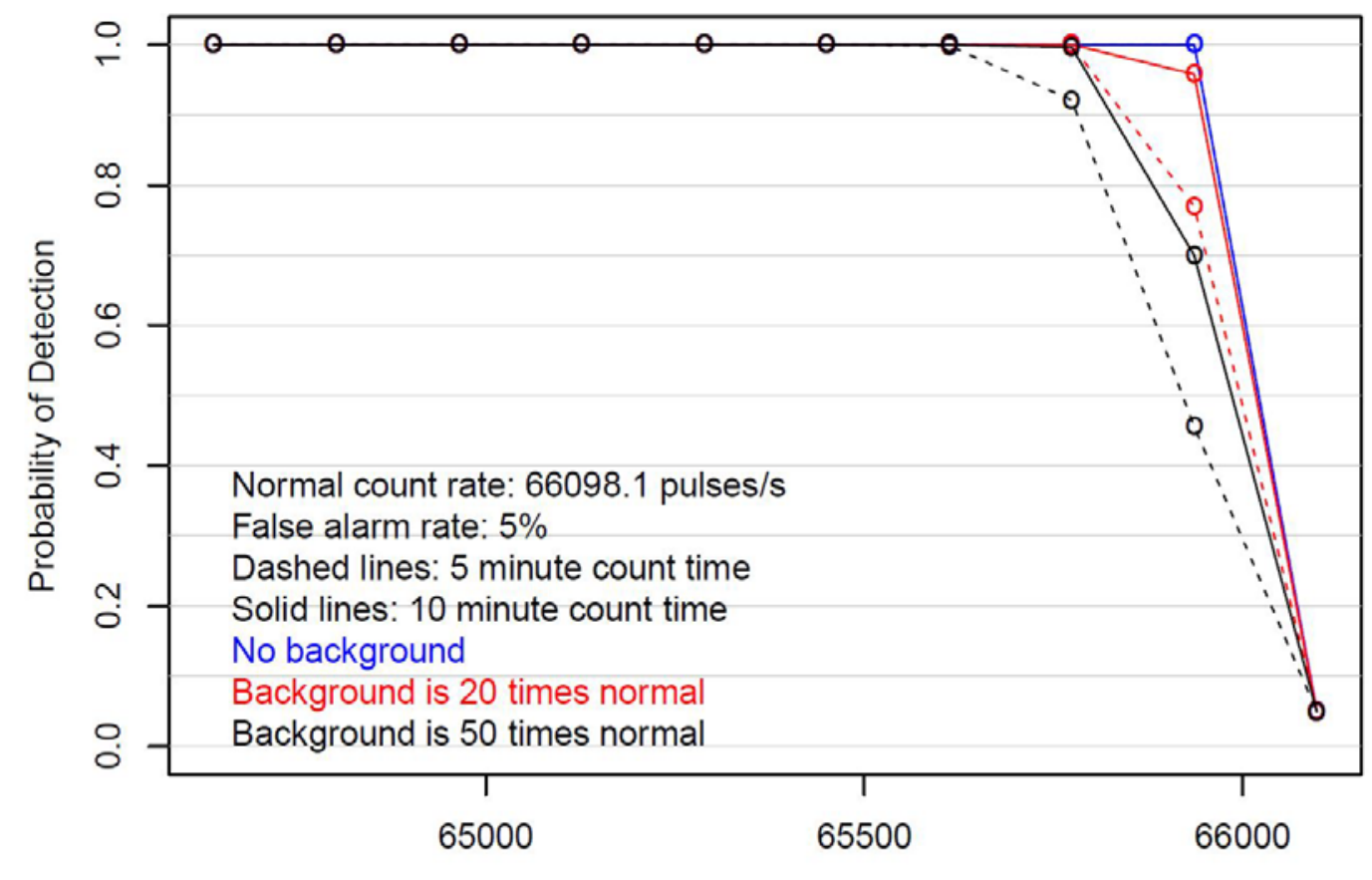

\begin{tabular}{|l|c|c|}
\hline & U Product & UTRU Product \\
\hline & pulses/s & pulses/s \\
\hline Normal & 7.9 & 66098.1 \\
\hline $1 \% \mathrm{Pu}$ & 36.8 & 64640.4 \\
\hline
\end{tabular}

Just like U Product Longer count times increase Pd Lower background increase $\mathrm{Pd}$

The reason for high background rates: Poisson data Stddev $=$ SQRT (mean) The square root is relatively small when counts are large

NOTE: dashed blue is under solid red

No Background Count Rates (pulses/s) 


\section{HDND Conclusion}

- The HDND has been shown to be HIGHLY effective at the specified locations to check U Product and U/TRU product for Pu diversions of relatively small amounts of $\mathrm{Pu}$

- Efficiencies of the HDND were not considered

- HDND Simulation modeling still needs to be done for confirmatory measurements 


\section{Microcalorimeter (Microcal)}




\section{Microcalorimeter}

\section{The microcalorimeter advantage:}

\section{X better energy resolution than semiconductor detectors}

- Reduce performance gap between NDA and DA

- Reduce reliance on sampling, mass spec, and chemical analysis

- Constrain diversion scenarios

- Better resolution enables better quantitative measurements
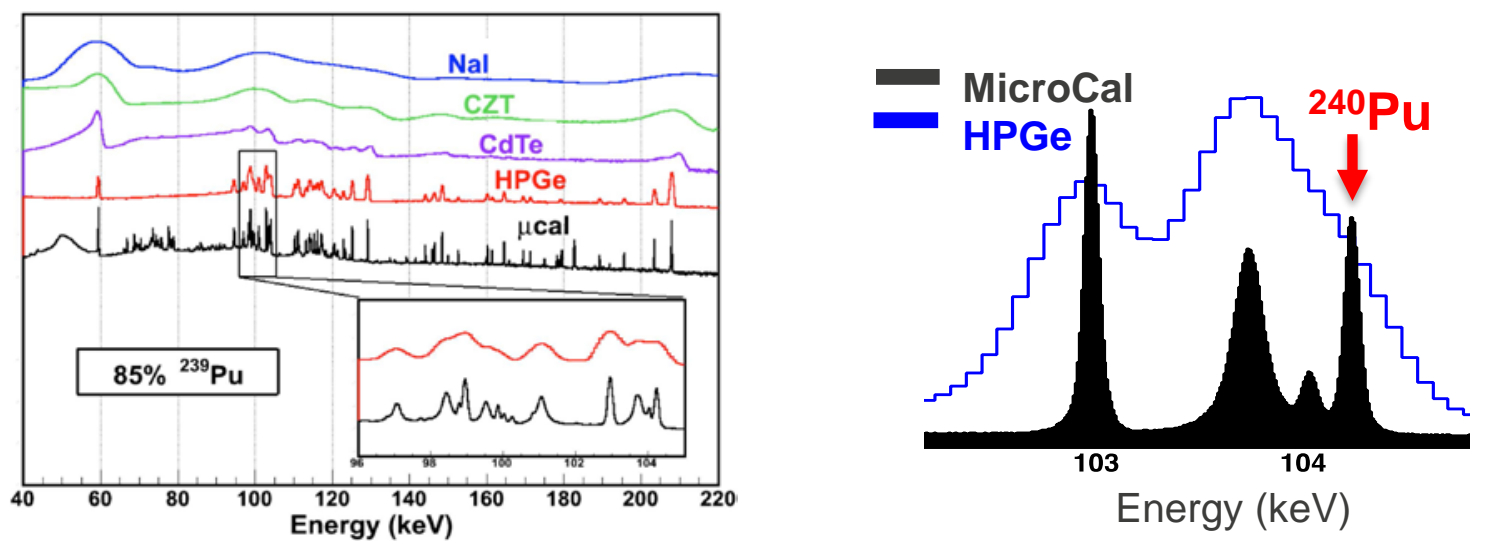

Potential applications in safeguards and material accounting:

- Spent fuel U/Pu elemental composition

- Fission products that track actinides

- Isotopic composition of U/TRU, Pu products

- Actinide content in wastes
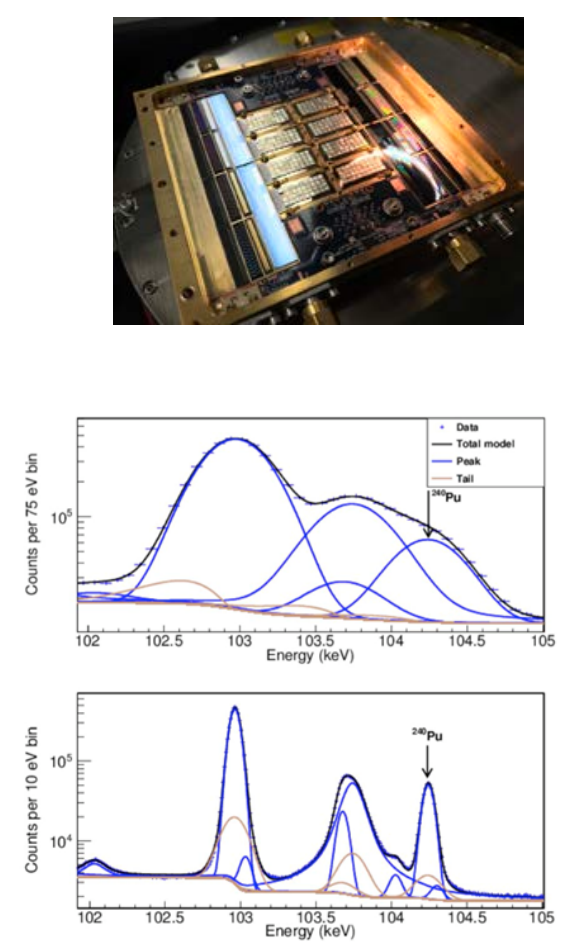

Figure 11 - Spectral region surrounding the $104.23 \mathrm{keV}^{240} \mathrm{Pu}$ peak measured with HPGe (top) and microcalorimeter (bottom). [Hoover, 2013] 


\section{Microcal Measurement Locations}

- ER Salt

- Determine the best visible peaks

- Source

- Determine IF there are viable peaks

- FP Waste

- For waste forms
Figure from SSPM - Cipiti

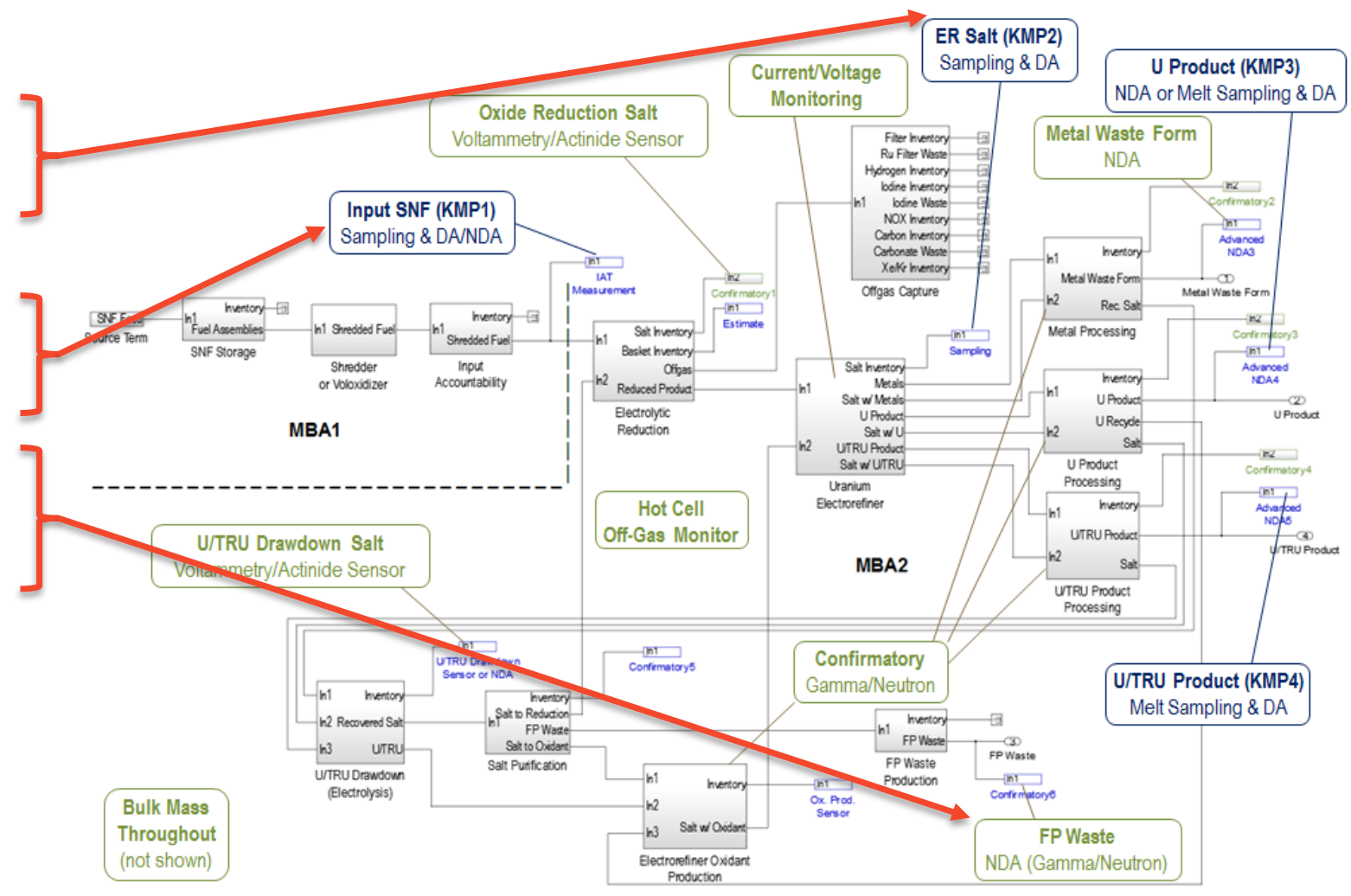




\section{Microcalorimeter}

- Gamma source terms created from mass data from SSPM measurement locations

- Locations evaluated

- Source term

- ER salt

- Fission Product Waste

- Most prominent peaks belong to $\mathrm{Am}, \mathrm{Eu}$, and $\mathrm{Pb}$

- Pu peaks difficult to identify above continuum

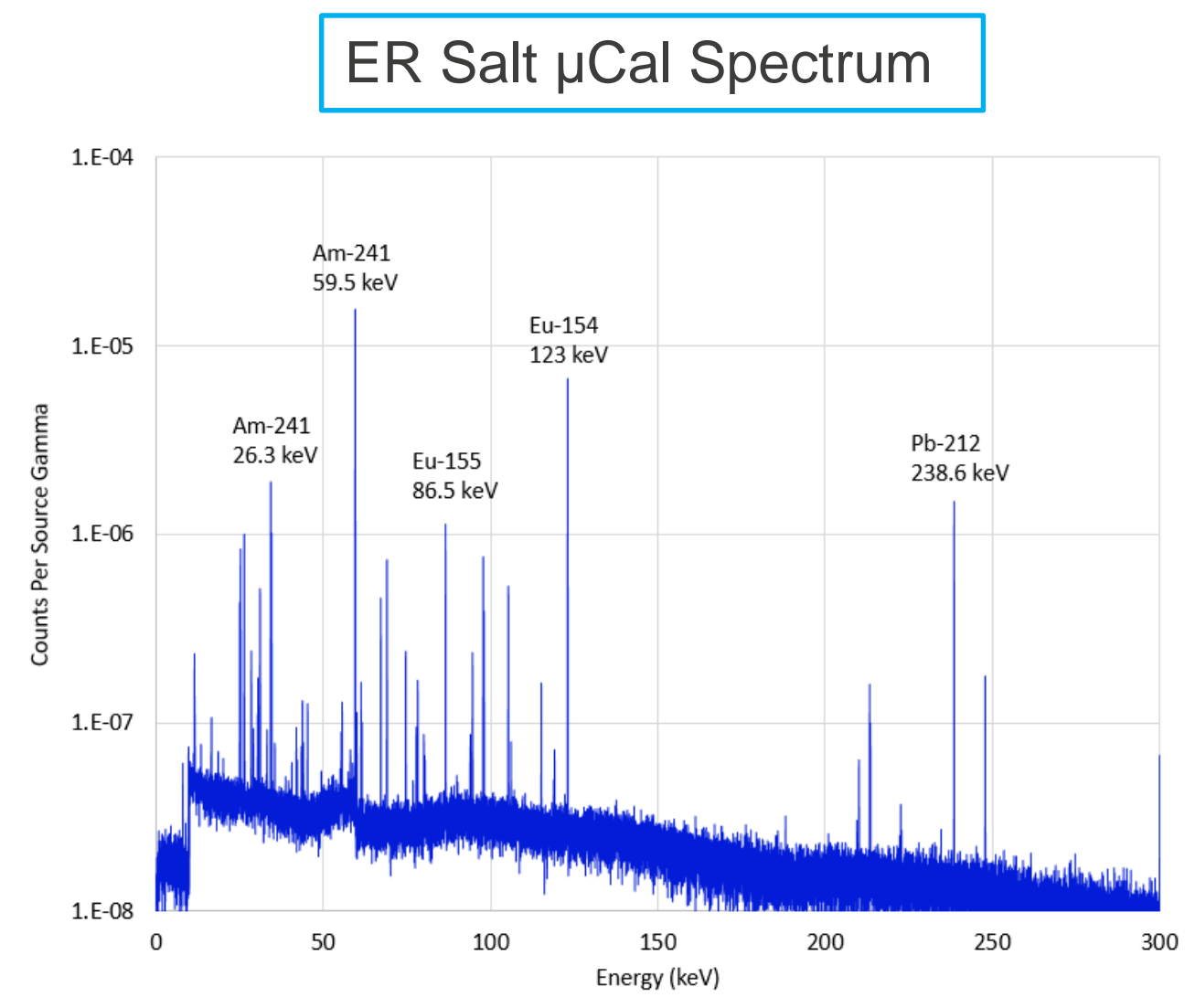




\section{Additional Intense Microcal Peaks to consider from Simulation}

\begin{tabular}{|c|c|c|c|c|c|}
\hline \multicolumn{2}{|c|}{ ER-Salt } & \multicolumn{2}{c|}{ FP Waste } & \multicolumn{2}{c|}{ Source Term } \\
\hline Energy (MeV) & Radionuclide & Energy (MeV) & Radionuclide & Energy (MeV) & Radionuclide \\
\hline 0.238632 & Pb-212 & 0.238632 & Pb-212 & 0.0595409 & Am-241 \\
\hline 0.1230706 & Eu-154 & 0.1230706 & Eu-154 & 0.1230706 & Eu-154 \\
\hline 0.0595409 & Am-241 & 0.247929 & Eu-154 & 0.238632 & Pb-212 \\
\hline 0.247929 & Eu-154 & 0.0865479 & Eu-155 & 0.0263446 & U-237/Am-241 \\
\hline 0.0865479 & Eu-155 & 0.1053083 & Eu-155 & 0.247929 & Eu-154 \\
\hline 0.1053083 & Eu-155 & 0.115183 & Pb-212 & 0.0865479 & Eu-155 \\
\hline 0.0263446 & Am-241 & 0.18822 & Eu-154 & 0.1053083 & Eu-155 \\
\hline 0.115183 & Pb-212 & 0.045299 & Eu-155 & 0.07466 & U-239/Am-243 \\
\hline 0.07466 & U-239/Am-243 & 0.0600086 & Eu-155 & 0.106123 & Np-239 \\
\hline 0.18822 & Eu-154 & 0.176314 & Sb-15 & 0.033196 & U-237/Am-241 \\
\hline
\end{tabular}




\section{ER-salt isotopes of interest}

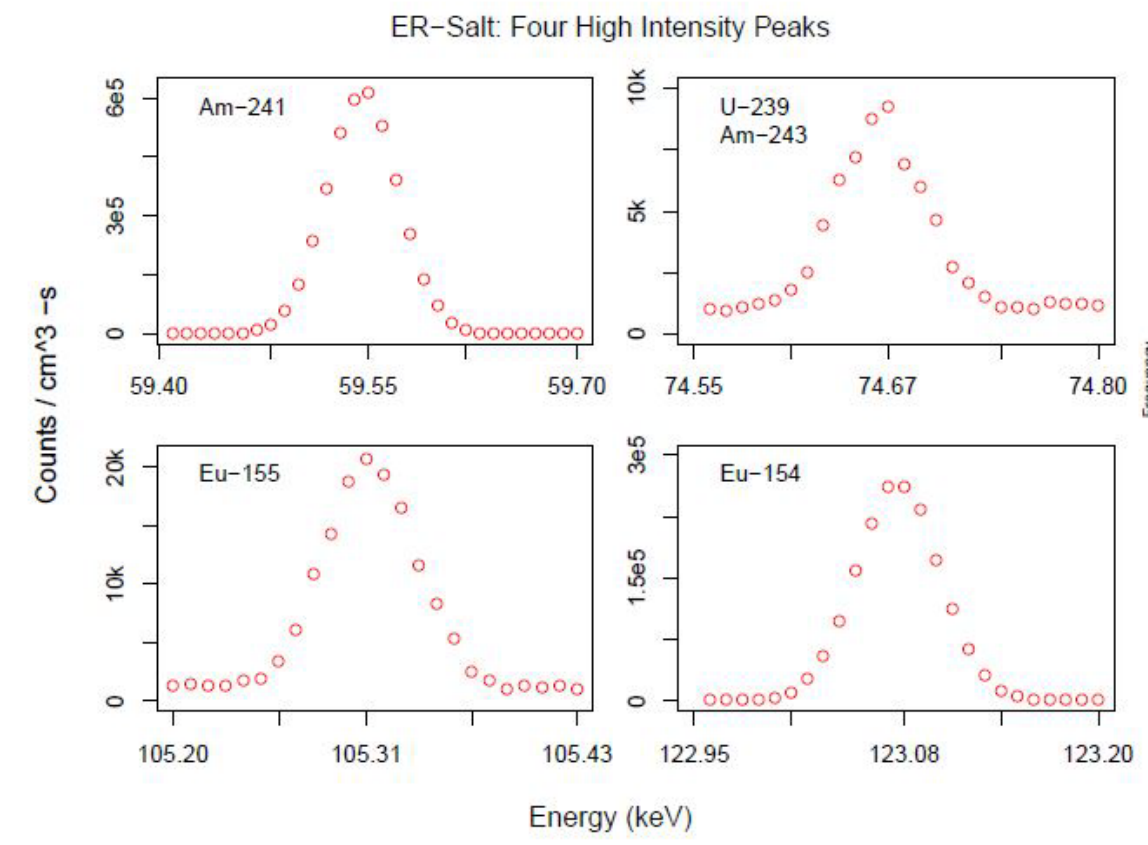

Probability of Detection for $1 \%$ and $1.5 \% \mathrm{Pu}$ Diverted, with 5\% False Alarm Rate for Eu-155
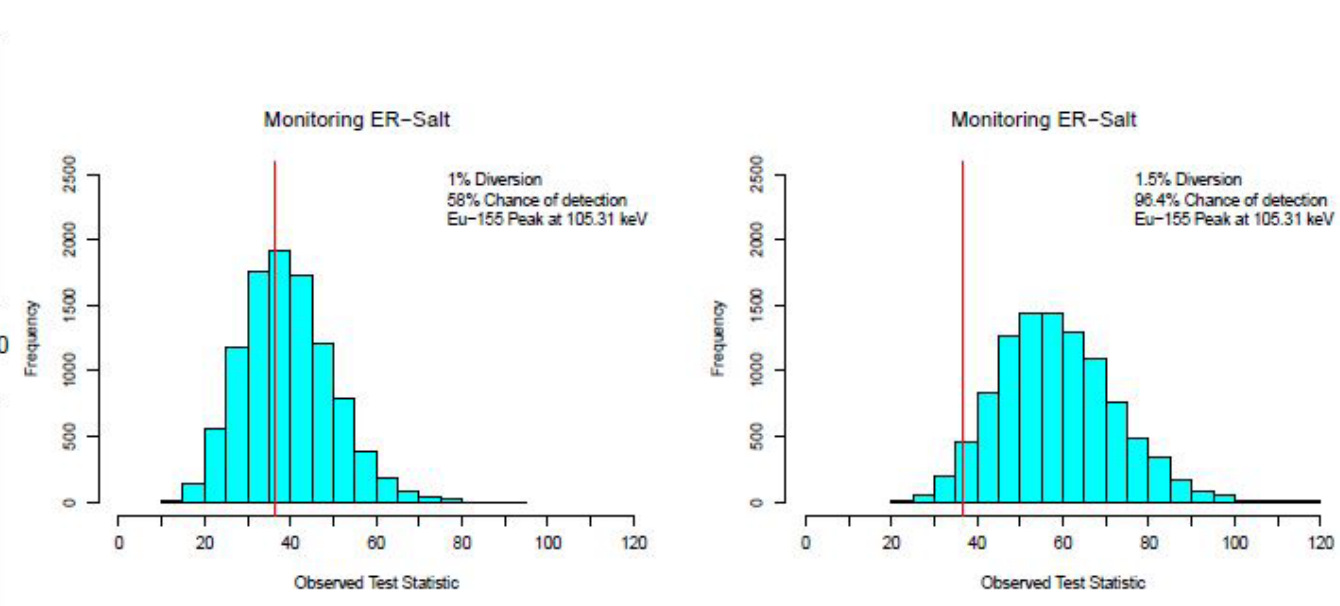


\section{FP Waste and Source isotopes of interest}

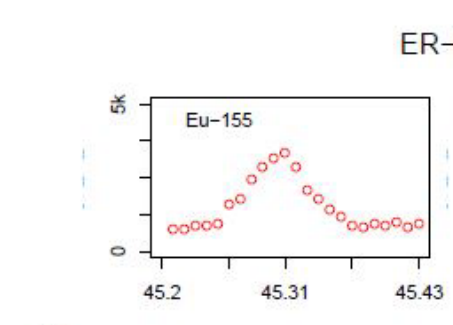

ER-FP Waste: High Intensity Peaks
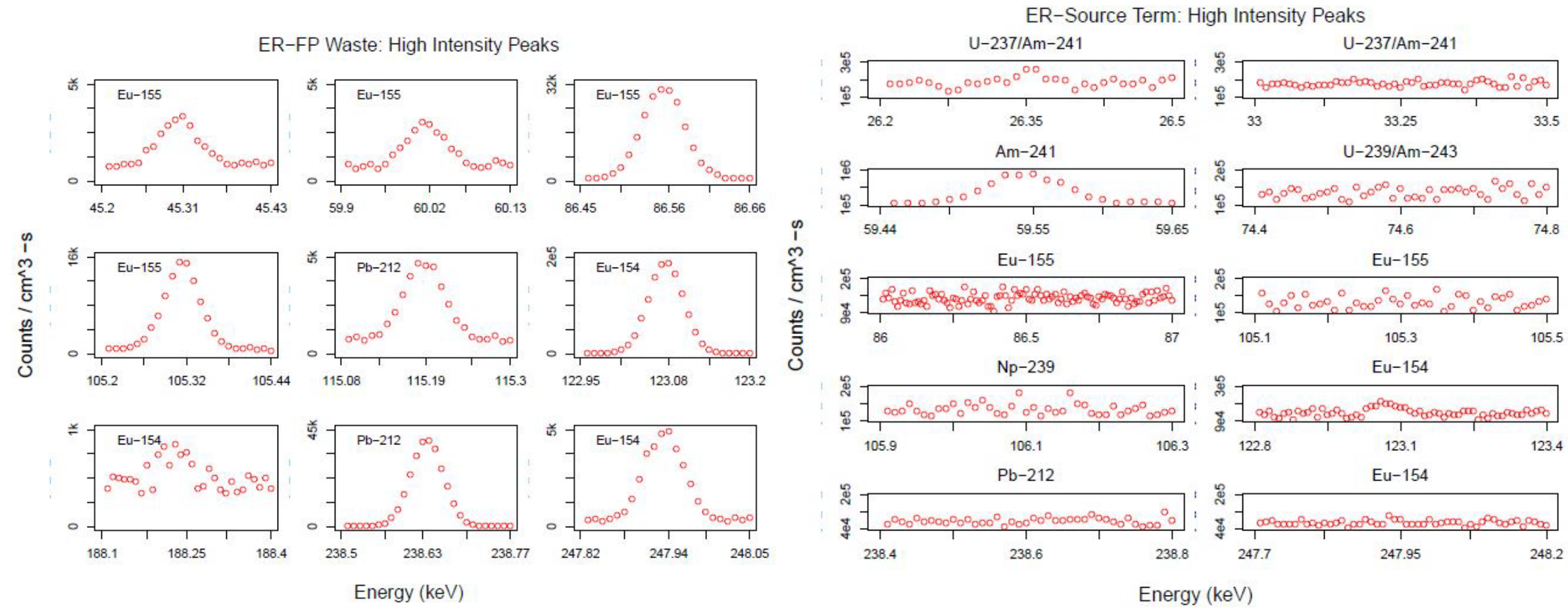

Energy (keV)

Energy (keV) 


\section{Source Microcal Detection}

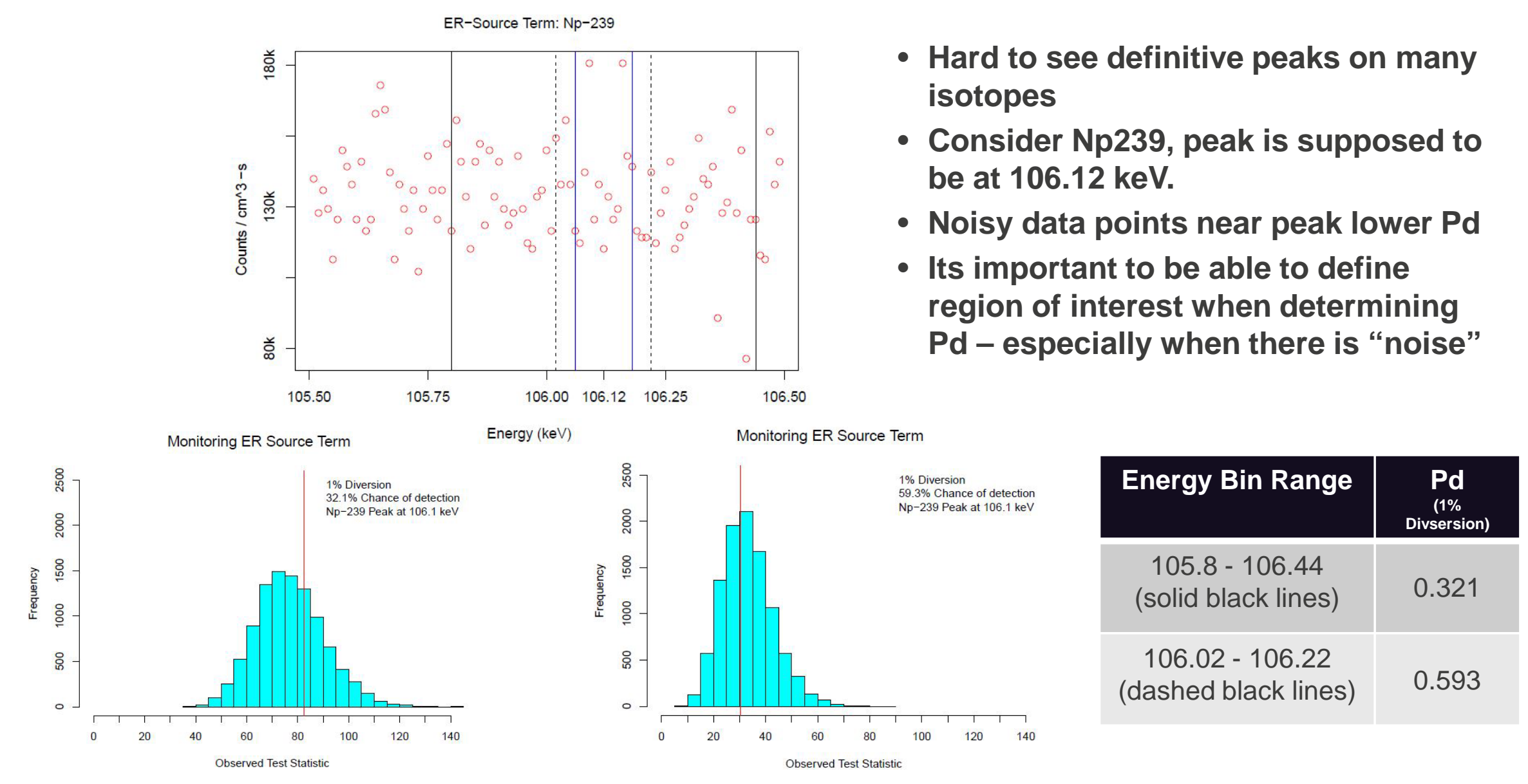




\section{Microcal Conclusions}

- Microcalorimeter is exceptional at detecting small diversions using intense peaks in the spectrum as the statistical data point

- Surrogate data for the Electro Refiner shows principle detecting elements such as Americium, Curium, Uranium, Neptunium are good indicators, if peaks standout

- Large peaks such as Eu-155, Am-241, Eu-154, U-239/Am-243 may be utilized for detection, once better isotopic data is known and an understanding how these isotopes changes according to diversions

- Only looked at variability in counting statistics and need to characterize other sources of uncertainty 


\section{Voltammetry \\ Ongoing Analysis....}




\section{Voltammetry Simulation}

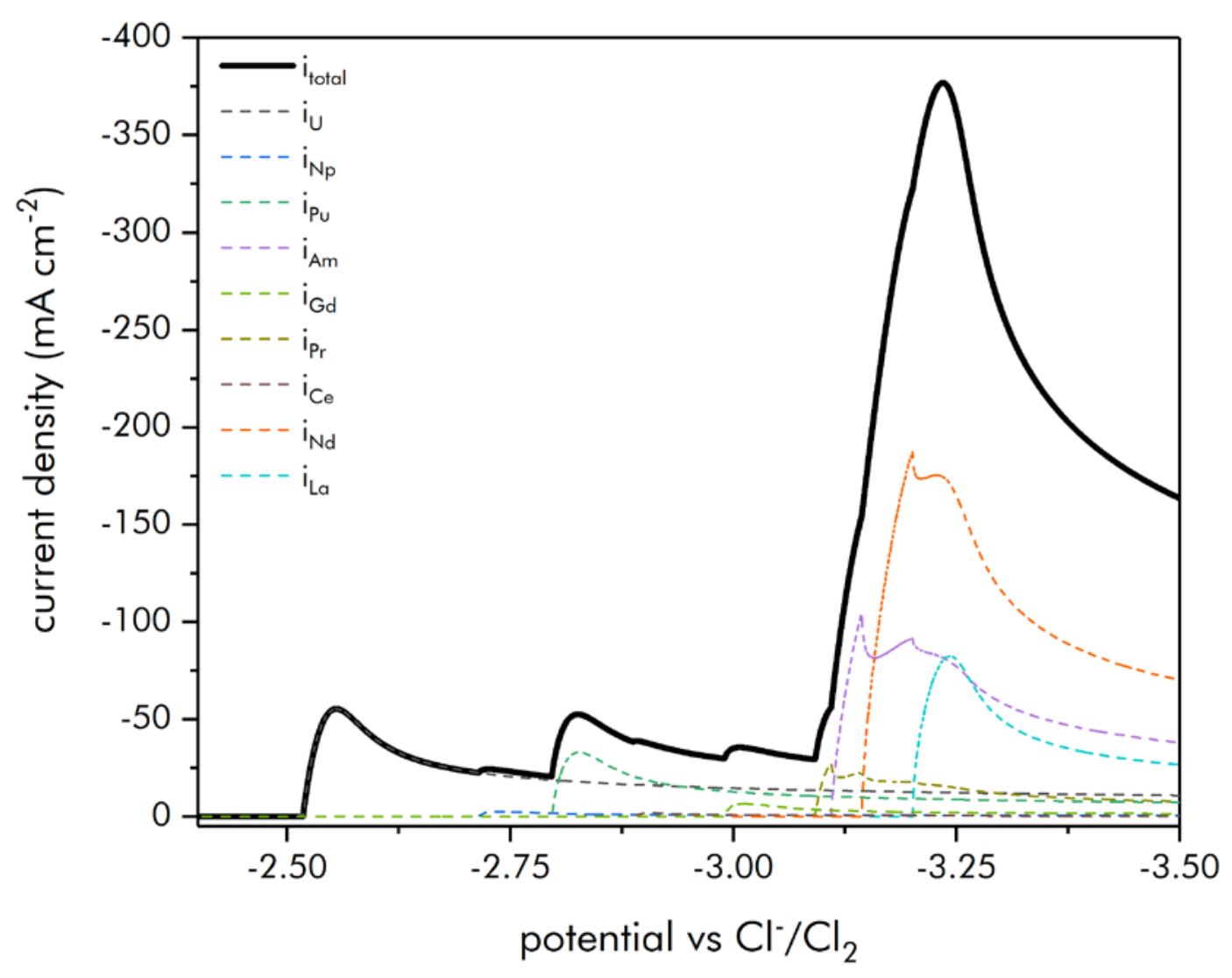

- Elemental mass data from the SSPM EChem model sent to Voltammetry development team at ANL

- N. Hoyt simulated the response of the instrument to the provided ER salt composition

- Black line represents total current density

- Dotted lines show species contributing to current density 


\section{Voltammetry Simulation, cont.}

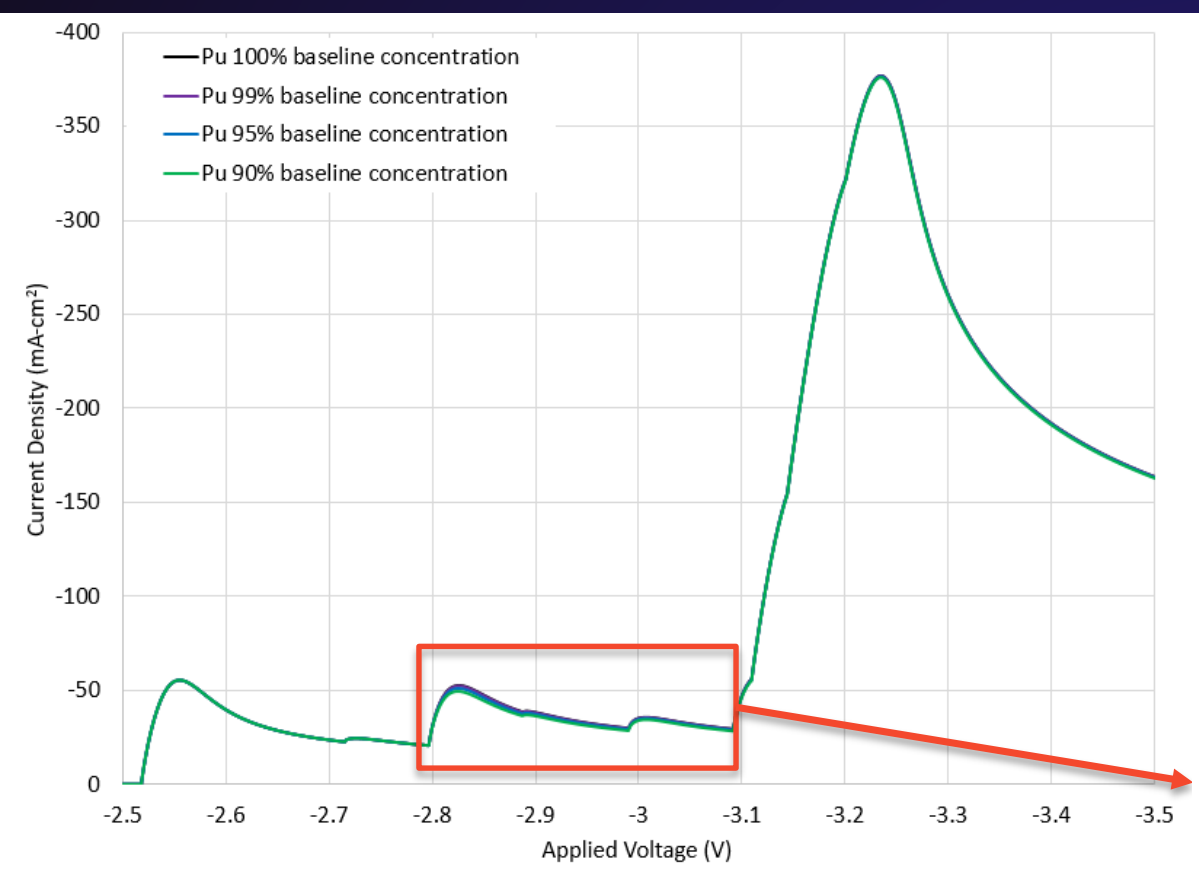

Repeated simulation, varying the $\mathrm{Pu}$ concentration of the ER salt to see how the waveform changes shape.

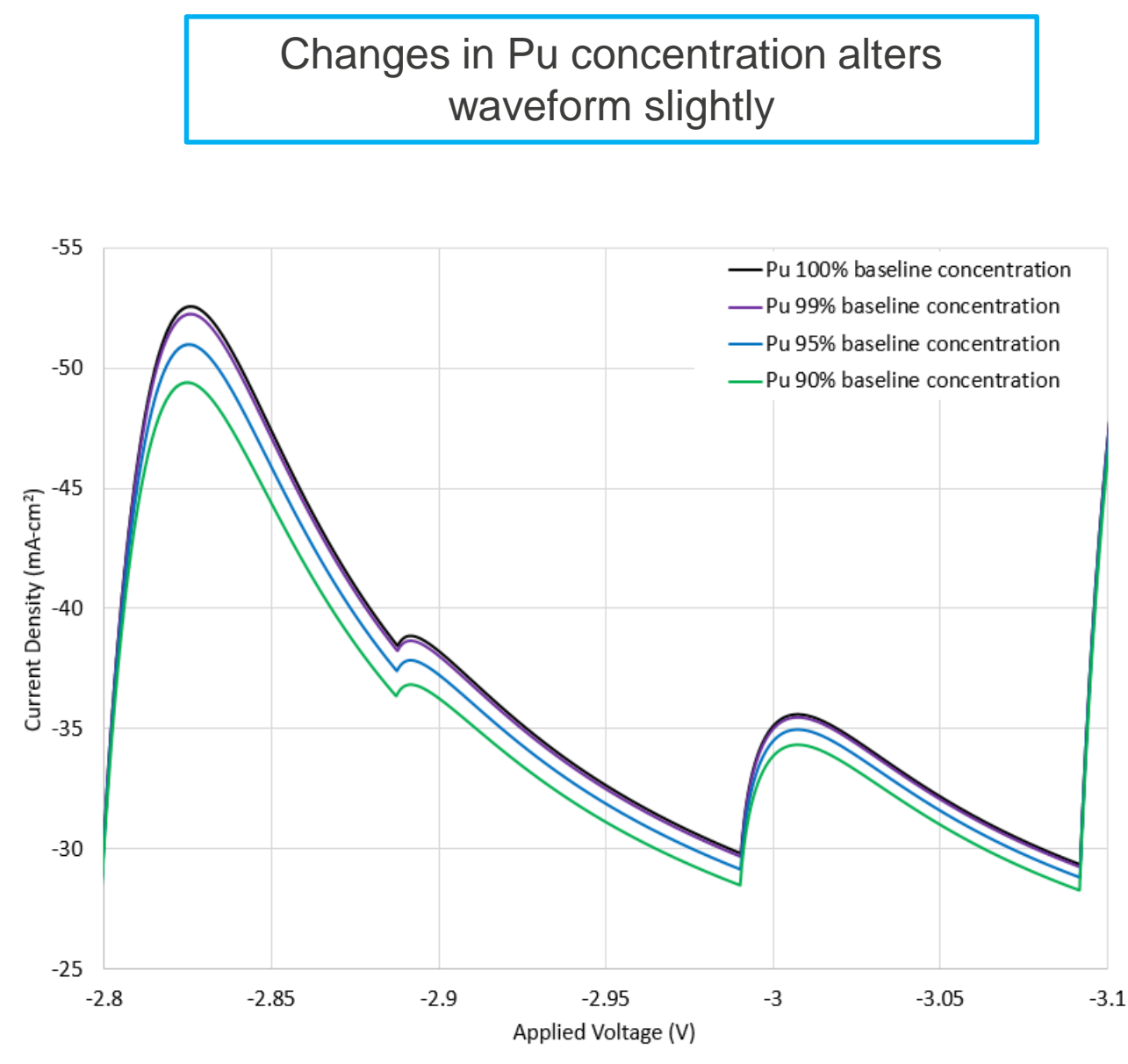




\section{Voltammetry Conclusion}

- Small change in Pu concentration alter the waveform

- Need to determine if the difference from normal to off-normal concentrations is significant enough for definitive conclusions to be made regarding diversion

- Current work is ongoing

- Thanks to ANL for simulated voltammetry response 


\section{Future Work}

- Analyze Confirmatory Measurement locations with simulated HDND

- Begin Voltammetry Integration Analysis with the data we've received

- Work with Bubbler SME's to determine integration approach, simulation and analysis

- Work with Microfluidic Sampler SME's to determine integration approach, simulation and analysis

- Data Flow Sheet development - currently using

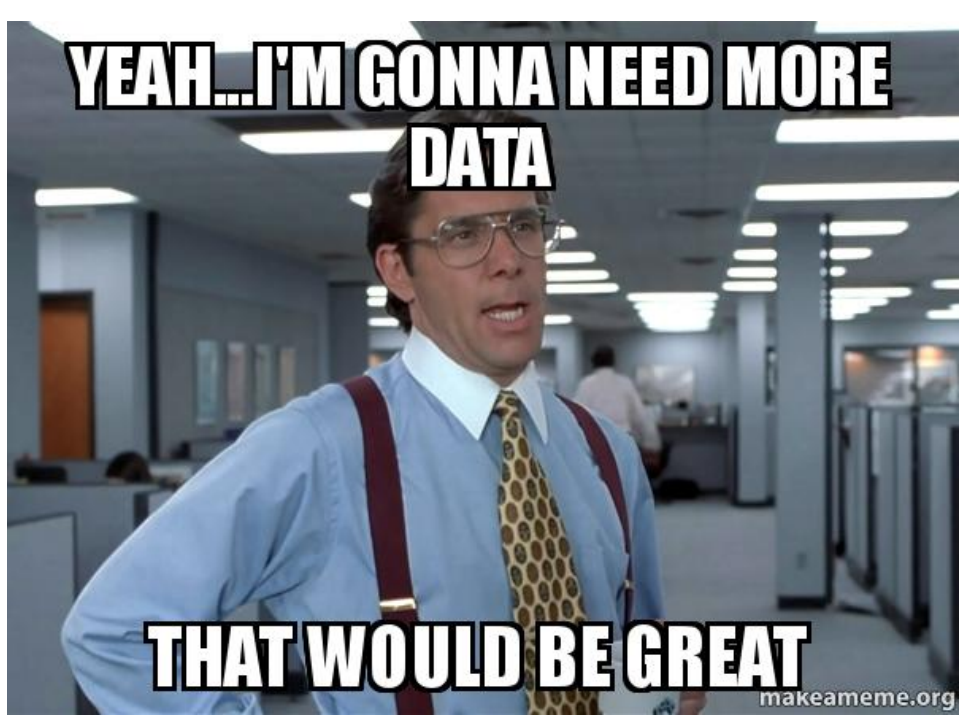
SSPM data, but need to double check integration of AMPYRE, DyER - what is the campaign wide process model flowsheet? 


\section{END}




\section{Test Statistic for Comparing Spectra of Counts}

$$
X^{2}=\sum_{k=1}^{N_{e}} \frac{\left(\text { Observed }_{k}-\text { Expected }_{k}\right)^{2}}{\text { Expected }_{k}}
$$

- Compare the observed counts in a particular energy bin to the expected counts-add up over all energy bins

- Expected counts from spectrum of in-control process

- $X^{2}$ has an approximate chi-square distribution

- Chi-squared distributions used for "goodness of fit"

- $X^{2}$ is large when counts are different enough-set a threshold for what is large

- Threshold determines false positive and detection rate 